\title{
Geostatistical estimation from radar altimeter data with respect to morphological units outlined by SAR data: application to Lambert Glacier/Amery Ice Shelf, East Antarctica
}

\author{
Ralf STOSIUS, ${ }^{1}$ Ute C. HERZFELD ${ }^{1,2}$ \\ ${ }^{1}$ Fachbereich Geographie/Geowissenschaften, Geomathematik, Universität Trier, D-54286 Trier, Germany \\ E-mail: stosius@denali.uni-trier.de \\ ${ }^{2}$ National Snow and Ice Data Center, Cooperative Institute for Research in Environmental Sciences, University of Colorado, \\ Boulder, CO 80309-0449, USA
}

\begin{abstract}
The objective of this paper is the comparison of two kriging methods, ordinary kriging and kriging within strata, for calculation of digital elevation models (DEMs) from radar altimeter data, and application to the Lambert Glacier/Amery Ice Shelf system, East Antarctica. Two new DEMs are presented. First, a DEM of the Lambert Glacier/Amery Ice Shelf system is calculated from 1997 European Remote-sensing Satellite-2 (ERS-2) radar altimeter (RA) data using geostatistical interpolation. RA data have high along-track density, but gaps between tracks are several kilometers, depending on the observation mode; this requires interpolation. Because the ice-stream/ice-shelf system is of primary interest in glaciological investigations, in the first approach a variogram characteristic of the Lambert Glacier ice surface is used. The resultant map has low errors for the glacier and the ice shelf. To match the surface characteristics of different morphological units that constitute the Lambert Glacier/Amery Ice Shelf region, a second DEM is constructed as follows: We utilize RADARSAT synthetic aperture radar (SAR) data that were collected in 1997 during the first Antarctic Imaging Campaign and composed into a $125 \mathrm{~m}$ backscatter-data mosaic by Jezek (1999) and we co-reference the $125 \mathrm{~m}$ mosaic with the altimetry-derived DEM. The Lambert Glacier/Amery Ice Shelf area is then subdivided into several regions which are homogeneous with respect to characteristic surface-morphological properties identified in the SAR mosaic. For those regions, a problem-oriented complex kriging method known as kriging within strata is performed, and the resulting DEM is compared to the DEM that was derived from kriging without regional subdivision.
\end{abstract}

\section{INTRODUCTION}

Mapping ice-surface elevation with continent-wide coverage is presently best achieved by satellite radar altimetry. Since Seasat in 1978, several satellite missions with radar altimetry have taken place. Since 1991, the European Remote-sensing Satellites ERS-1 and -2 have provided radar altimeter (RA) data that can be used for monitoring changes in Antarctic and Arctic ice mass balance by time series of elevation models built with RA data of subsequent observations. Monitoring of ice mass balance is important for assessing sea-level changes, and accurate elevation models serve as data sources for numerical models of ice movement. The satellite missions differ in scientific goals, as well as in schedules of repeat time and coverage. RA data have a semirhombic ground-track pattern with gaps of several kilometers between tracks, depending on latitude and observation method. Thus, interpolation of RA data is required to determine an elevation model of the Antarctic ice sheet. Interpolation is best performed using methods from geostatistics, the theory of regionalized variables (Matheron, 1963; Herzfeld and others, 1993; Herzfeld, 2004). There are highresolution elevation models from stereo images of synthetic aperture radar (SAR) data using interferometric analysis, but until now only regional elevation models exist from SAR. During the 1997 RADARSAT-1 Antarctic Imaging Campaign, SAR data covering the entire continent were collected. We utilize these data in the form of a $125 \mathrm{~m}$ pixel backscatter mosaic compiled by Jezek (1999) to improve mapping from RA data for the Lambert Glacier/Amery Ice Shelf system.
However, SAR data are not elevation data, but backscatter data, hence elevation may only be inferred indirectly. Here, we take a different approach in that SAR data are used only as an aid in delineating different regions according to their morphological characteristics. Subsequently a complex geostatistical method known as kriging within strata (KWS) (Goovaerts, 1997) or stratified kriging is applied to interpolating elevation values from RA data in each of those regions. KWS refers to mapping within geological units in a sedimentary-geology setting. In our situation, the units in which different kriging interpolators are applied are morphological units of the Lambert Glacier/Amery Ice Shelf system. The interpolators are specific to regional morphology in the variograms that determine the interpolation kernel; the type of interpolator is still ordinary kriging. The resultant digital elevation models (DEMs) are presented and compared.

\section{DATA ACQUISITION}

The nominal area of interest is $63-75^{\circ} \mathrm{S}, 59-79^{\circ} \mathrm{E}$. The RA data of the map area are transformed by Universal Transverse Mercator (UTM) projection, resulting in an orthogonal coordinate system which is essential for kriging. The map area extends from 7578 to $8322 \mathrm{~km}$ UTM South and 215 to $785 \mathrm{~km}$ UTM East related to the central meridian at $69^{\circ} \mathrm{E}$ (zone 42). To get enough RA data for interpolation and to ensure nearly the same time interval as the SAR data, RA data from the period 1 August-31 October 1997 are used. The exact repeat observation method employed during 


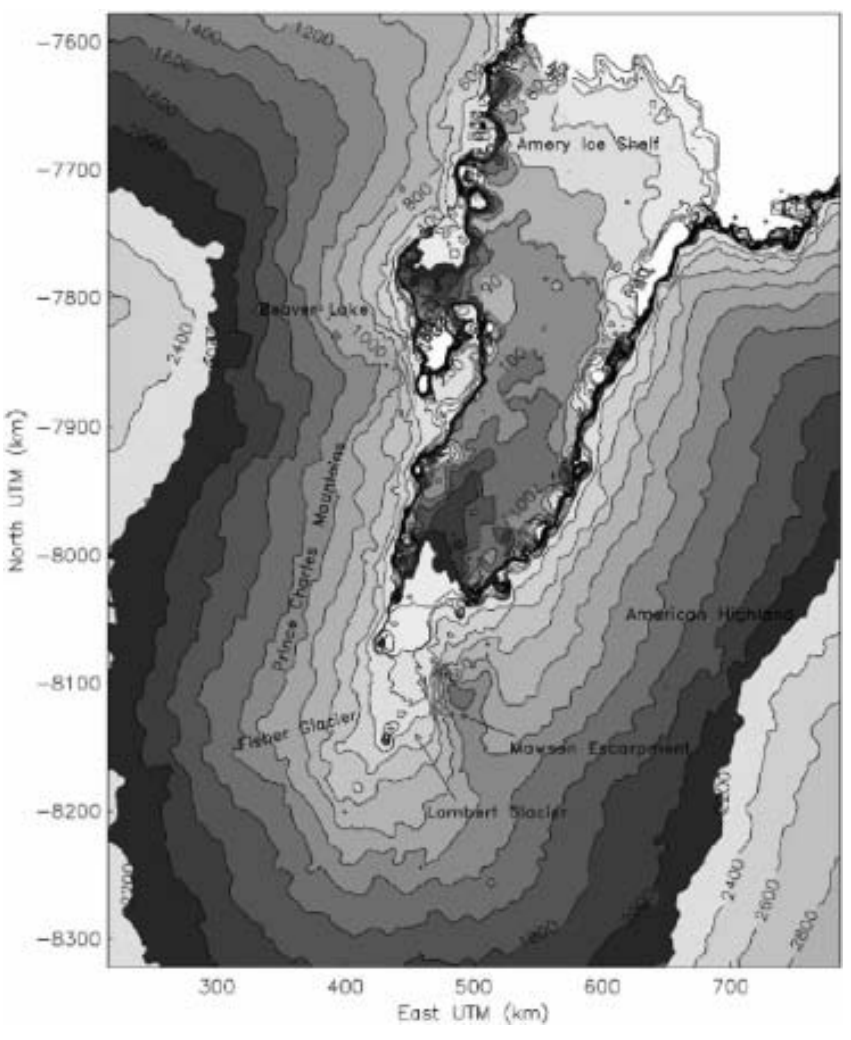

Fig. 1. Contour plot of a DEM with $3 \mathrm{~km}$ grid spacing deduced from 1997 ERS-2 RA elevations from the Lambert Glacier/Amery Ice Shelf system using ordinary kriging with a Gaussian variogram $\left(C_{0}=25 \mathrm{~m}^{2}, C_{1}=18 \mathrm{~m}^{2}\right.$, range $\left.=16000 \mathrm{~m}\right)$. Coordinates in $\mathrm{km}$ with respect to central meridian at $69^{\circ} \mathrm{E}$, UTM zone 42 . Elevations in meters with respect to WGS84 ellipsoid, 40-140 m with $10 \mathrm{~m}$ contour lines, $140-200 \mathrm{~m}$ with $20 \mathrm{~m}$ contour lines and $200-2800 \mathrm{~m}$ with $200 \mathrm{~m}$ contour lines.

this time causes gaps of 15-25 km between parallel groundtrack orbits each with several parallel repeat tracks separated by only a few to a hundred meters. There are missing data due to tracking errors, especially at the transition from the ice shelf to the surrounding ranges.

The RA data were processed by the Ice Sheet Altimetry Group at NASA Goddard Space Flight Center, Greenbelt, MD, USA (Zwally and others, 1983), using the method for retracking by Martin and others (1983), slope correction as described by Brenner and others (1983), Goddard Earth Model (GEM) T2 orbits (Martin and others, 1983) for data reduction, corrections for atmospheric effects and solid Earth tides as described by Zwally and others (1983), and watervapor corrections. The elevation is given with reference to the World Geodetic System 1984 ellipsoid (WGS84).

The first Antarctic Imaging Campaign of RADARSAT-1 lasted from 9 September to 20 October 1997. During this period, RADARSAT operated in a left-looking mode so that the entire continent could be mapped. During the first Antarctic Mapping Mission (AMM-1) a seamless digital SAR mosaic with $125 \mathrm{~m}$ resolution was created at Byrd Polar Research Center, Columbus, OH, USA. The data provided are grey values of radar backscatter intensity deduced from $25 \mathrm{~m}$ resolution swaths used for the mosaic (Jezek, 1999; Jezek and RAMP Product Team, 2002). From these data a subset of Lambert Glacier/Amery Ice Shelf covering the same area as the RA data is extracted, georeferenced and converted to UTM.

\section{GEOSTATISTICAL METHODS FOR ELEVATION MAPPING}

Interpolation of corrected and collocated RA data is carried out using geostatistical methods known as 'kriging'. Kriging comprises a family of interpolation/extrapolation methods based on the least-squares optimization principle (Matheron, 1963; Journel and Huijbregts, 1978). Kriging consists of two steps: (1) analysis of spatial structures (variography); and (2) estimation (kriging). The variogram analysis may be carried out (a) for the whole map area, using all data (a technique not applied here for computational and glaciological reasons), (b) using data from a representative subarea for mapping the whole area (used in the construction of the first DEM), and (c) varying regionally for units in the map area (used in the KWS method). The estimation step is performed for each grid node, based on data collected in its neighborhood and on the appropriate variogram model.

\subsection{Structure analysis: variography}

First an experimental variogram is calculated according to

$$
\gamma(h)=\frac{1}{2 n} \sum_{i=1}^{n}\left[z\left(x_{i}\right)-z\left(x_{i}+h\right)\right]^{2},
$$

where $z\left(x_{i}\right), z\left(x_{i}+h\right)$ are measurements at locations $x_{i}$, $x_{i}+h$, respectively, inside a region $\mathrm{D}$, and $n$ is the number of pairs separated by the vector $h$. The experimental variograms are calculated from measurements and grouped in distance classes. A variogram model describes the type of transition from the strong covariation between closely neighboring samples to weaker covariation of samples farther apart. The variogram model is characterized by its function type, which has to meet the positive-definiteness criterion to ensure existence and uniqueness of the solution of the kriging system. The model is defined by three parameters: nugget effect $\left(C_{0}\right)$, total sill $\left(C_{0}+C_{1}\right)$ and range (a). The nugget effect is the residual variance of resampling in the same location and it also contains contributions caused by surface morphological features below the resolution of the altimeter footprint (called the support). The total sill is close to the total variance of the data. The concept of a regionalized variable perceives that closely neighboring measurements have a higher covariance than measurements spaced farther apart. For distances increasing from the support to the range, the variogram increases and the regionalization effect decreases; for distances beyond the range, the regionalized variable behaves like a random variable (probabilistically), and data with a distance larger than or equal to the range all have the same influence on the interpolated value (numerically).

\subsection{Ordinary kriging}

For the kriging method the value $z_{0}=z\left(x_{0}\right)$ at a position $x_{0}$ is estimated by

$$
z_{0}^{*}=\sum_{i=1}^{n} \alpha_{i} z_{i} \quad \text { with } \quad \alpha_{i} \in \mathbb{R}
$$

with data $z_{i}=z\left(x_{i}\right)$ at locations $x_{i}(i=1, \ldots, n)$ in a neighborhood of the position $x_{0}$ and weights $\alpha_{i}$. To obtain an unbiased estimate, the following condition is required:

$$
\sum_{i=1}^{n} \alpha_{i}=1
$$

This method is called ordinary kriging. 


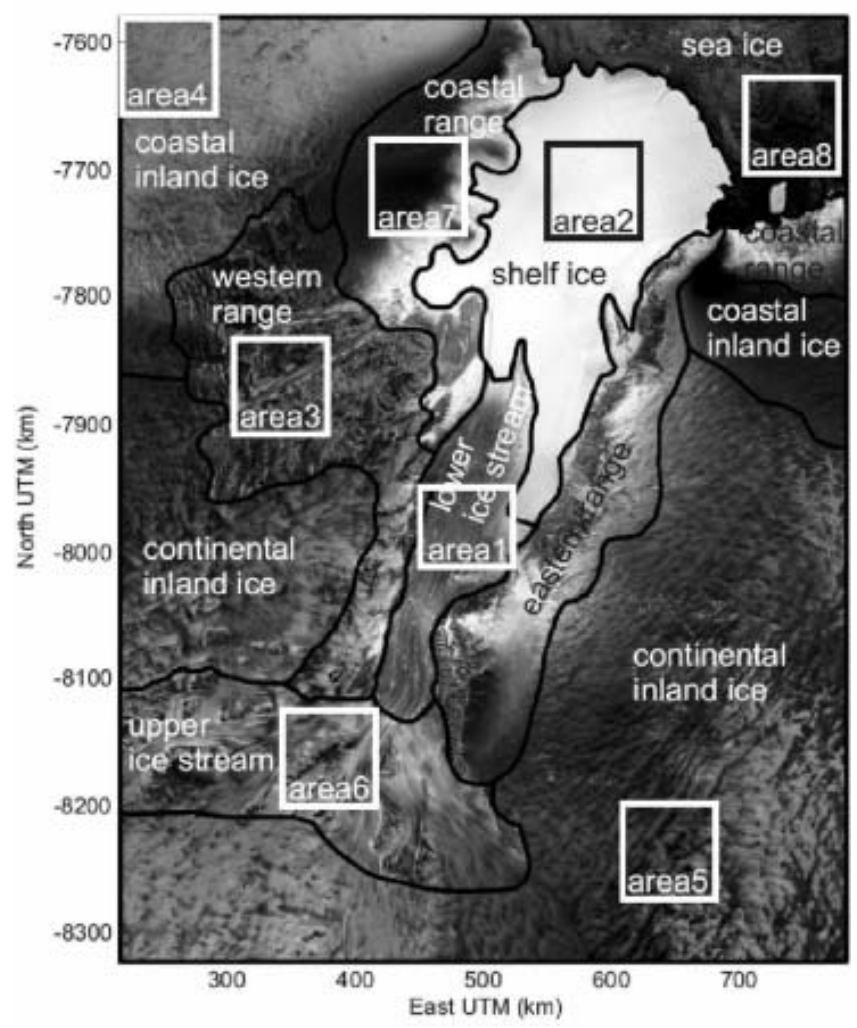

Fig. 2. Regions and areas used for KWS deduced from the RADARSAT-1 SAR mosaic (Jezek, 1999) of the Lambert Glacier/ Amery Ice Shelf system.

For simplicity, we use only one global Gaussian variogram model, with the following parameters: $C_{0}=25 \mathrm{~m}^{2}$, $C_{1}=18 \mathrm{~m}^{2}, a=16000 \mathrm{~m}$. The variogram was fitted to ERS1 RA data from 1995 from around the grounding zone of Lambert Glacier (Herzfeld and others, 2000). It was fitted for the grounding zone of Lambert Glacier because this part is of essential interest for mass-balance studies. In this part of the glacier, the estimation error is low (Herzfeld and others, 1993). We choose this model to insure that the same interpolator is used for the ERS-1 and ERS-2 elevation models, and hence that the new elevation model presented in this paper may be compared to published elevation models of the Lambert Glacier/Amery Ice Shelf system (Herzfeld and others, 1996, 1997, 2000; Herzfeld, 1999; Herzfeld and Matassa, 1999). Figure 1 shows the contour plot of elevations using ordinary kriging for estimation of a $3 \mathrm{~km}$ grid.

\subsection{Kriging within strata}

Because the entire area of interest contains many morphologically different regions, ranging from at this scale rather smooth inland ice to rugged mountainous terrain, more than one variogram will be needed to capture the spatial variability of each region adequately. Therefore the Lambert Glacier/Amery Ice Shelf study area is subdivided into apparently homogeneous morphological regions. For this segmentation, visually detectable features in the SAR mosaic are used to define the borders between morphological regions. The assignment of an RA datum to a region is performed by a point-in-polygon algorithm. In every region a small area (Fig. 2) of up to $75 \mathrm{~km}^{2}$ is extracted for fast variogram calculation.

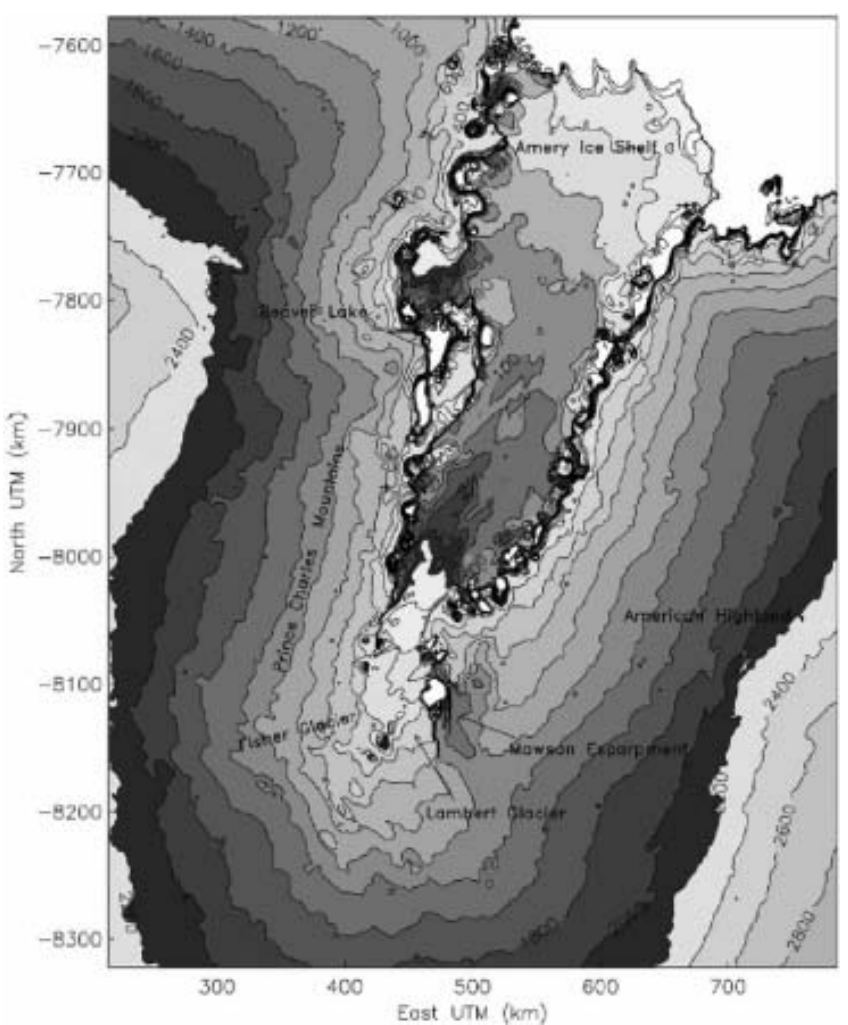

Fig. 3. Same as Figure 1 but using KWS (ordinary kriging with locally variable variograms) instead of ordinary kriging.

The influence of the semi-rhombic data distribution with ascending and descending track directions is very strong. The number of data pairs with distance $h$ equal to the distance between parallel track orbits increases dramatically and causes peaks in the experimental variogram. Therefore only directional variograms in the direction of the ascending and descending ground tracks are used. To take into account the semi-rhombic structure of the data distribution, a quadrant search with eight sectors is performed. The variogram models fitted to these variograms are supposed to have the same nugget and sill. If the ranges of the variograms from the two directions differ, the spatial structure is anisotropic.

The spatial structure of areas 1-6 is fitted best by two nested Gaussian variogram models with nugget effect, which is

$\gamma(h)=C_{0}+C_{1}\left[1-\exp \left(-\frac{3 h^{2}}{a_{1}{ }^{2}}\right)\right]+C_{2}\left[1-\exp \left(-\frac{3 h^{2}}{a_{2}{ }^{2}}\right)\right]$,

where $C_{0}$ is the nugget effect, $C_{1}$ and $a_{1}$ are the sill and range parameter for the first and $C_{2}$ and $a_{2}$ are the parameters for the second spatial structure. In area 7 the anisotropy is too complex to fit adequate directional variogram models, so we use only a global nested Gaussian model. Area 8 is the sea-ice region which is fitted by a global exponential model. The fitting is performed using SFIT, an automatic fitting program of Jian and others (1996). SFIT uses the Levenberg-Marquardt method, which is one of the best for parameter estimation of non-linear functional models. For every region the characteristic variograms are calculated for a lag increment of $300 \mathrm{~m}$ which is the mean distance between subsequent measurements along track 
Table 1. Areas and corresponding nested variogram model parameters. Range parameters $(a)$ in $\mathrm{m}$, sill parameters $(C)$ in $\mathrm{m}^{2}$

\begin{tabular}{|c|c|c|c|c|c|c|c|c|c|c|}
\hline Area & Region & $C_{0}$ & Type & $C_{1}$ & $a_{1}$ asc & $a_{1}$ des & Type & $C_{2}$ & $a_{2}$ asc & $a_{2}$ des \\
\hline 1 & Lower ice stream & 5 & Gauss & 20 & 7400 & 6724 & Gauss & 125 & 15583 & 37583 \\
\hline 2 & Shelf ice & 0.4 & Gauss & 0.55 & 5931 & 5504 & Gauss & 7.9 & 30561 & 27646 \\
\hline 3 & West/east range & 40 & Gauss & 2361 & 33286 & 19241 & Gauss & 10972 & 69441 & 66678 \\
\hline 4 & Coastal inland ice & 10 & Gauss & 156 & 7165 & 36394 & Gauss & 71273 & 150000 & 92441 \\
\hline 5 & Continental inland ice & 18 & Gauss & 163 & 4370 & 9715 & Gauss & 5440 & 40664 & 62502 \\
\hline 7 & Coastal range & 300 & Gauss & 700 & 40000 & 40000 & Gauss & 27100 & 53000 & 53000 \\
\hline 8 & Sea ice & 0.05 & exponential & 0.12 & 1038 & 1038 & & & & \\
\hline
\end{tabular}

Note: asc, ascending direction; des, descending direction.

after collocation. The areas and their corresponding variogram models are listed in Table 1.

In every region the estimation of elevation is executed separately by ordinary kriging using GSLIB (Geostatistical Software Library, Stanford University) routines from Deutsch and Journel (1998). Anisotropies are incorporated by assigning variograms derived for descending tracks to $45^{\circ}$ and variograms derived for ascending tracks to $135^{\circ}$. Then the regions are combined again into one DEM and map (Fig. 3). This method of subdivision and recombination is known from geological applications as KWS (Goovaerts, 1997) or stratified kriging.

\section{COMPARISON OF DIFFERENT KRIGING METHODS AND RESULTANT DEMS: DISCUSSION AND CONCLUSIONS}

\subsection{Cross-validation}

To compare the two methodologies applied in this paper, we perform cross-validation (Deutsch and Journel, 1998).

$$
\mathrm{ME}=\frac{1}{n} \sum_{i=1}^{n}\left[z\left(x_{i}\right)-z^{*}\left(x_{i}\right)\right] .
$$

For each region the mean error (ME) between the true values $z\left(x_{i}\right)$ and the estimated values $z^{*}\left(x_{i}\right)$ at every RA measurement position $x_{i}$ is calculated for ordinary kriging and KWS respectively. The absolute mean errors for KWS are lower than for ordinary kriging within most of the regions (Table 2). Only within the eastern range and the eastern coastal range do the absolute mean errors become higher. This may be because no specific variograms are calculated within these regions but they were erroneously assumed to be described by the same variogram as the western range and the western coastal range. The calculated errors show the mean deviation of the estimated values from the known measurement values in meters. Cross-validation provides only an indicator of the quality of the estimation, but not a numerical error value of the DEM.

\subsection{Surface morphology}

The contour lines of the map in Figure 1 are generally smoother than those of the map in Figure 3. The variogram model used for kriging the map in Figure 1 has a high nugget-effect-to-sill ratio, which is necessary (1) to counteract the effect of the ground-track pattern on the experimental variogram and (2) to model the smooth surface of the glacier adequately (for a definition of the nugget-effect ratio, see
Herzfeld and others, 2000). The surface morphology of all other units is hence neglected, and KWS provides a method to remedy this situation. Other authors (e.g. Fricker and others, 2000) limit the area of DEM calculation to the main Lambert Glacier and Amery Ice Shelf for glaciological reasons and thus avoid the problem of matching different morphological types. Purely mathematical interpolation algorithms are not capable of morphological modeling and consequently are only useful for one unit (e.g. low-slope interior of Antarctica in Bamber (1994)). Fricker and others (2000) utilize ordinary kriging, but take an automated, leastsquares approach to variogram modeling and fit ascending and descending tracks separately, which may have led to overfitting. An expression of this is too rough and noisy contours on the glacier and ice-shelf surfaces (parameters are not published).

The salient problem is to distinguish mathematically between altimeter-signal properties and errors, on the one hand, and geophysical or morphological properties of the surface, on the other hand, and hence between variogram modeling and variogram fitting. The surface of the icestream/ice-shelf system is best represented in the map in Figure 1. The morphological complexity of the large Lambert Glacier/Amery Ice Shelf region led to selection of eight different units, which necessitated spatial information from non-RA data; a solution was facilitated by SAR data. In variogram modeling for each unit, a semi-automated approach was applied to distinguish specific properties. As a side effect, altimeter errors that appear in the experimental variograms are also modeled. When kriging with more complex variograms of different regions and considering anisotropies, the different morphological features of the regions become more prominent, in particular those of the rougher environments, which is correct (map in Fig. 3). However, the close fitting of experimental variograms that is the result of automated fitting of variogram models has the effect that track-pattern-induced artefacts and other errors may also be picked up in combination with morphological properties, as is visible in central areas of the glacier and ice shelf (Fig. 3). We conclude that KWS is advantageous in that variograms specific to the local morphology may be used if variograms can be modeled adequately. The possibilities of modeling are also limited by the altimeter data quality.

Where RA data are missing due to tracking errors, estimation errors occur in both maps, especially at the transition between the ice shelf and the surrounding ranges. Some of these estimation errors in the map in Figure 3 may be intensified due to a border effect, i.e. too few data near 
Table 2. Cross-validation mean errors (ME) for ordinary kriging (OK) and kriging within strata (KWS) for each region in meters

\begin{tabular}{lrr}
\hline Region & ME OK & ME KWS \\
\hline Sea ice & -0.3073 & 0.0543 \\
Shelf ice & -0.0436 & 0.0047 \\
Eastern range & 0.1678 & 0.2366 \\
Lower ice stream & -1.3679 & -0.0081 \\
Upper ice stream & 0.0818 & 0.0443 \\
Coastal range (west) & 0.3442 & -0.0203 \\
Coastal range (east) & -0.4291 & -0.4805 \\
Western range & 0.6961 & -0.0175 \\
Coastal inland ice (west) & 0.0252 & 0.0067 \\
Coastal inland ice (east) & 0.5703 & 0.0003 \\
Continental inland ice (west) & 0.1538 & 0.0028 \\
Continental inland ice (east) & 0.0948 & 0.0037 \\
& & \\
\hline
\end{tabular}

the borders of a region. To overcome this problem, a fuzzier definition of the borders, such as border zones instead of border lines between regions, may be useful.

\section{SUMMARY}

We have utilized a synopsis of ERS-2 RA data with RADARSAT-1 SAR data for calculation of DEMs of Lambert Glacier/Amery Ice Shelf, using two different kriging algorithms. Ordinary kriging with a modeling approach to variography proved best for mapping the ice-stream/iceshelf system itself, at the same time reducing altimetry artefacts. Kriging within strata is an advanced kriging method that facilitates mapping of large areas with morphologically different geographical regions, as demonstrated for the Lambert Glacier/Amery Ice Shelf region and its surroundings. Morphological units were delineated using co-referenced SAR data. The KWS method involved calculation of variograms, fitting anisotropic variogram functions and application of ordinary kriging as the interpolation algorithm for all data within each morphological province. Resultant maps exhibit the different morphological characteristics of each geographical region, but also follow altimeter errors more closely. Cross-validation values are lower for KWS than for ordinary kriging for a large part of the mapped area, which is, albeit not a numerical error quantity, an indication of the quality of the map.

Last but not least, accuracy of a DEM and its morphological quality are limited by the survey instrumentation, and more precise mapping of surface structures may be expected from a combination of advanced geomathematical methods and data from advanced altimeters such as RA-2 (Envisat), GLAS (ICESat) and CryoSat instruments.

\section{ACKNOWLEDGEMENT}

The authors thank T.H. Jacka for comments on the manuscript.

\section{REFERENCES}

Bamber, J. L. 1994. A digital elevation model of the Antarctic ice sheet derived from ERS-1 altimeter data and comparison with terrestrial measurements. Ann. Glaciol., 20, 48-54.

Brenner, A. C., R. A. Bindschadler, R. H. Thomas and H. J. Zwally. 1983. Slope-induced errors in radar altimetry over continental ice sheets. J. Geophys. Res., 88(C3), 1617-1623.

Deutsch, C. L. and A. G. Journel. 1998. GSLIB geostatistical software library and user's guide. Second edition. Oxford, etc., Oxford University Press. (Applied Geostatistics Series.)

Fricker, H. A., G. Hyland, R. Coleman and N.W. Young. 2000. Digital elevation models for the Lambert Glacier-Amery Ice Shelf system, East Antarctica, from ERS-1 satellite radar altimetry. J. Glaciol., 46(155), 553-560.

Goovaerts, P. 1997. Geostatistics for natural resources evaluation. Oxford, etc., Oxford University Press.

Herzfeld, U.C. 1999. Geostatistical interpolation and classification of remote sensing data from ice surfaces. Int. J. Remote Sensing, 20(2), 307-327.

Herzfeld, U.C. 2004. Atlas of Antarctica: topographic maps from geostatistical analysis of satellite radar altimeter data. Heidelberg, etc., Springer Verlag.

Herzfeld, U.C. and M.S. Matassa. 1999. An atlas of Antarctica north of $72.1 \mathrm{~S}$ from GEOSAT radar altimeter data. Int. J. Remote Sensing, 20(2), 241-258.

Herzfeld, U.C., C.S. Lingle and L.-her Lee. 1993. Geostatistical evaluation of satellite radar altimetry for high-resolution mapping of Lambert Glacier, Antarctica. Ann. Glaciol., 17, 77-85.

Herzfeld, U. C., H. Mayer, C. A. Higginson and M. Matassa. 1996. Geostatistical approaches to interpolation and classification of remote-sensing data from ice surfaces. In Guyenne, T. D., ed. Proceedings of the Fourth Circumpolar Symposium on Remote Sensing of the Polar Environments, 29 April-1 May 1996, Lyngby, Denmark. Noordwijk, European Space Agency. ESA Publications Division, 59-63. (Esa SP-391.)

Herzfeld, U.C. and 6 others. 1997. Monitoring changes of ice streams using time series of satellite-altimetry-based digital terrain models. Math. Geol., 29(7), 859-890.

Herzfeld, U.C., R. Stosius and M. Schneider. 2000. Geostatistical methods for mapping Antarctic ice surfaces at continental and regional scales. Ann. Glaciol., 30, 76-82.

Jezek, K. C. 1999. Glaciological properties of the Antarctic ice sheet from RADARSAT-1 synthetic aperture radar imagery. Ann. Glaciol., 29, 286-290.

Jezek, K.C. and RAMP Product Team. 2002. RAMP AMM-1 SAR image mosaic of Antarctica. Fairbanks, AK, Alaska SAR Facility, in association with the National Snow and Ice Data Center, Boulder, CO. (http://nsidc.org/data/docs/daac/ nsidc0103_ramp_mosaic.gd.html.)

Jian, X., R. A. Olea and Y.-S. Yu. 1996. Semivariogram modelling by weighted least squares. Computers Geosci., 22(4), 384-397.

Journel, A. G. and C. J. Huijbregts. 1978. Mining geostatistics. Second edition. New York, etc., Academic Press.

Martin, T. V., H.J. Zwally, A.C. Brenner and R.A. Bindschadler. 1983. Analysis and retracking of continental ice sheet radar altimeter waveforms. J. Geophys. Res., 88(C3), 1608-1616.

Matheron, G. 1963. Principles of geostatistics. Econ. Geol., 58(8), 1246-1266.

Zwally, H.J., R. A. Bindschadler, A.C. Brenner, T. V. Martin and R. H. Thomas. 1983. Surface elevation contours of Greenland and Antarctic ice sheets. J. Geophys. Res., 88(C3), 1589-1596. 